\title{
8
}
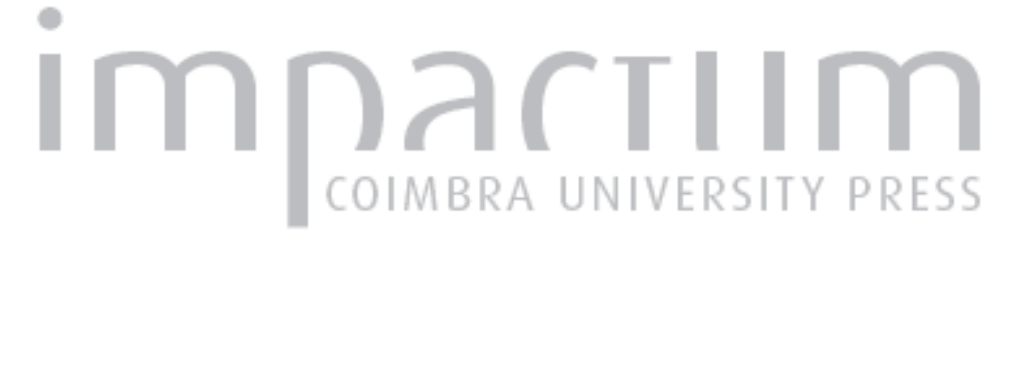

\section{Protocolo de observação de morfologia dentária: sistematização de observações em contexto profissional e de formação académica} \author{
Autor(es): $\quad \begin{aligned} & \text { Marado, Luís Miguel; Cunha, Claudia; Scott, G. Richard; Silva, Ana } \\ & \text { Maria }\end{aligned}$
}

Publicado por: Imprensa da Universidade de Coimbra

URL

persistente:

URI:http://hdl.handle.net/10316.2/43422

DOI:

DOI:http://doi.org/10.14195/2182-7982_34_7

Accessed : $\quad$ 26-Apr-2023 12:55:59

A navegação consulta e descarregamento dos títulos inseridos nas Bibliotecas Digitais UC Digitalis, UC Pombalina e UC Impactum, pressupõem a aceitação plena e sem reservas dos Termos e Condições de Uso destas Bibliotecas Digitais, disponíveis em https://digitalis.uc.pt/pt-pt/termos.

Conforme exposto nos referidos Termos e Condições de Uso, o descarregamento de títulos de acesso restrito requer uma licença válida de autorização devendo o utilizador aceder ao(s) documento(s) a partir de um endereço de IP da instituição detentora da supramencionada licença.

Ao utilizador é apenas permitido o descarregamento para uso pessoal, pelo que o emprego do(s) título(s) descarregado(s) para outro fim, designadamente comercial, carece de autorização do respetivo autor ou editor da obra.

Na medida em que todas as obras da UC Digitalis se encontram protegidas pelo Código do Direito de Autor e Direitos Conexos e demais legislação aplicável, toda a cópia, parcial ou total, deste documento, nos casos em que é legalmente admitida, deverá conter ou fazer-se acompanhar por este aviso.

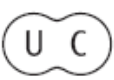




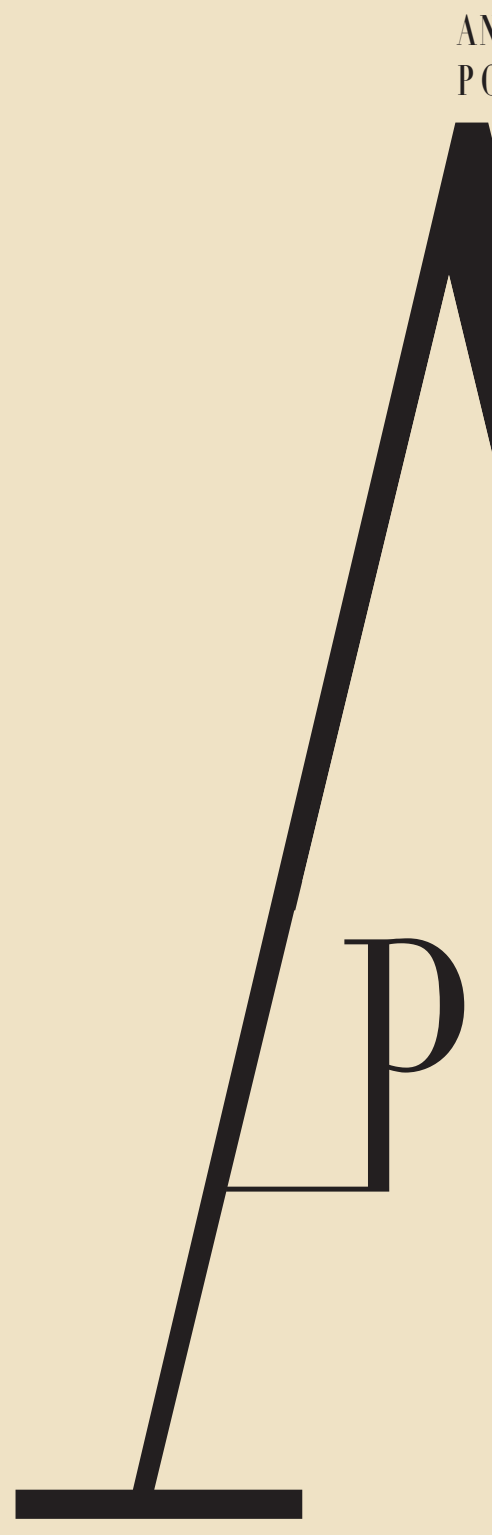

IITROPOLOGIA

PORTUGUESA 


\title{
Protocolo de observação de morfologia dentária: sistematização de observações em contexto profissional e de formação académica
}

\section{Protocol for scoring dental morphology: systematization of observation in professional and academic training contexts}

\author{
Luís Miguel Marado ${ }^{1,2, a^{*}}$, Claudia Cunha ${ }^{3,4 b}$, G. Richard Scott ${ }^{5}$, \\ Ana Maria Silva ${ }^{4,6,7 c}$
}

Resumo Em bioarqueologia, a morfologia dentária centra-se em variáveis da coroa e da raiz que podem estar presentes ou ausentes e, quando presentes, frequentemente exibem variação na expressão, de ligeira a pronunciada. Estudos em gémeos e famílias demonstram que estes caracteres são predominan-

\begin{abstract}
In bioarchaeology, dental morphology centers on crown and root traits that are either present or absent and, when present, commonly exhibit a range of expression from slight to pronounced (e.g., shovel-shaped incisors, Carabelli's cusp). Twin and family studies show these variables are determined prima-
\end{abstract}

\footnotetext{
1 Unidade de Arqueologia - Universidade do Minho, Braga, Portugal.

${ }^{2}$ Lab2PT - Laboratório de Paisagens, Património e Território - Universidade do Minho, Braga, Portugal.

${ }^{3}$ Programa de Capacitação Institucional MCTI/MPEG, Coordenação de Ciências Humanas, Museu Paraense Emílio Goeldi, Belém, Pará, Brasil.

${ }^{4}$ Laboratório da Pré-história, CIAS - Departamento de Ciências da Vida, Universidade de Coimbra.

${ }^{5}$ Department of Anthropology - University of Nevada Reno, United States.

${ }^{6}$ UNIARQ - WAPS. Centro de Arqueologia da Universidade de Lisboa.

${ }^{7}$ Laboratório de Antropologia Forense, Centro de Ecologia Funcional - Departamento de Ciências da Vida, Universidade de Coimbra.

a orcid.org/0000-0003-0116-9433

${ }^{b}$ orcid.org/0000-0002-5073-1704

c orcid.org/0000-0002-1912-6581

* Corresponding author: luismarado@gmail.com

DOl: https://doi.org/10.14195/2182-7982_34_7

Artigo recebido a 28 de outubro de 2016 e aceite a 26 de abril 2017
} 
temente determinados por fatores genéticos. Numerosos estudos de populações demonstraram que os caracteres não-métricos dentários são ferramentas poderosas para aferir a afinidade biológica entre amostras ao nível local, regional e global. O objetivo deste trabalho é providenciar a profissionais ou estudantes uma lista de 27 caracteres dentários essenciais que constituem o número mínimo de variáveis para caracterizar as dentições de amostras esqueléticas ou vivas. Recomendações adicionais para além da "lista de caracteres não-métricos essenciais" focam-se em (a) métodos de registo de desgaste oclusal, (b) no formato da base de dados de morfologia dentária, (c) nas bases do método de contagem individual e (d) na importância de avaliar o erro intraobservador (ou consistência no registo).

Palavras-chave: Antropologia Dentária; caracteres não-métricos dentários; afinidade biológica; método em Paleoantropologia.

\section{Introdução}

A morfologia dentária corresponde à variação fenética visível na dentição decídua (Lukacs e Kuswandari, 2013) e permanente. Tal variação está representada nas raízes e coroas dentárias (Scott et al., 2016), no osso alveolar ou perfil oclusal (p. ex.: em caracteres como o diastema do incisivo central superior [lrish, 1998] ou a rotação mesiolingual destes mesmos dentes [Turner et al., 1991]), assim como na junção esmalte-dentina, no caso de al- rily by genetic factors. Numerous population studies have demonstrated that nonmetric dental traits are powerful tools for inferring biological affinity among samples at the local, regional, and global levels. The goal of this work is to provide professionals and students with a list of 27 essential dental traits, which constitute the minimum number of variables to characterize skeletal or living samples' dentitions. Additional recommendations beyond the 'essential non-metric dental trait' list focus on (a) methods of scoring occlusal wear, (b) the format of the dental morphological data base, (c) the basics of the individual count method, and (d) the importance of evaluating intraobserver error (scoring consistency).

Key words: Dental Anthropology; nonmetric dental traits; biological affinity; method in Paleoanthropology.

gumas variáveis da coroa (p. ex.: Skinner e Gunz, 2010). Essa variação pode ser registada através da observação de dezenas de caracteres não-métricos (ou discretos) (Turner et al., 1991; Scott e Turner, 1997; Scott et al., 2016).

A sistematização metodológica mais relevante em morfologia dentária é o Arizona State University Dental Anthropology System (Turner et al., 1991). Este sistema baseia-se em definições textuais dos caracteres não-métricos dentários (a) mais fáceis de registar, (b) com menor alteração 
causada por desgaste dentário, (c) menos afetados por dimorfismo sexual, (d) de lenta evolução e (e) utilidade no cálculo de afinidade biológica entre populações. A variabilidade dos caracteres é expressa em escala ordinal (graus), procurando pontos equidistantes na distribuição da sua expressão em vez da tradicional definição dicotómica de presença/ausência (Turner et al., 1991). Vários dos caracteres selecionados por Turner e colegas (1991) são acompanhados de placas de referência em gesso que representam tridimensionalmente a variação identificada. Estas placas permitem padronizar observações e aumentar a concordância entre observadores e a consistência intraobservador (Scott e Turner, 1997; Hillson, 2005).

Os traços discretos da dentição são afetados por fatores ambientais, mas o fator primordial de variação é genético (Hughes e Townsend, 2013). A componente genética da variação morfológica dentária é considerada estável, pouco sujeita a pressões evolutivas em períodos inferiores a milhares de anos (Willermet e Edgar, 2009; Hughes e Townsend, 2013) - veja-se, no entanto, Mizoguchi (2013). Assim, a morfologia dentária, uma subárea da Antropologia Dentária, pode ser usada para aferir as relações biológicas entre diferentes amostras à escala global (Scott e Turner, 1997; Hanihara, 2008), regional (Irish, 1993; Manabe et al., 2011) e local (Alt e Vach, 1998), através de comparações de natureza quantitativa ou estatística (Harris, 2008) das frequências de presença de múltiplos caracteres discretos. Além disto, estas comparações podem fazer-se independentemente da cronologia, se for possível aceder a amostras dentárias em quantidade e qualidade suficiente. Através da estimativa das relações biológicas entre amostras é possível avaliar o impacto biológico de migrações (envolvendo processos de deriva genética e fluxo génico), procurando responder a questões antropológicas, arqueológicas e históricas (Scott e Turner, 1997; Jackes et al., 1997; 2001; Silva, 2012; Marado, 2014; Cunha, 2015; Marado e Silva, 2017).

Em Portugal, o estudo de morfologia dentária assumiu maior expressão nos finais dos anos 90 do século XX e inícios do século XXI, aquando dos estudos sobre as populações pré-históricas (Jackes et al., 1997; 2001; Silva, 2002; 2012). Mais recentemente verificou-se a proliferação de estudos de morfologia dentária nas dissertações de Licenciatura (p. ex.: Gomes, 2005; Rodrigues, 2005; Simão, 2005; Costa, 2006; Fernandes, 2006; Lucas, 2006; Pinto, 2006; Pombal, 2006; Costa, 2007), de Mestrado (p. ex:: Marques, 2007; Godinho, 2008; Tereso, 2009; Gonçalves, 2010; Graça, 2010; Marado, 2010; Cunha, 2011; Leandro, 2011; Jesus, 2012; Pinto, 2012; Rodrigues, 2013; Coelho, 2013) e de Doutoramento (Pereira, 2009; Marado, 2014; Cunha, 2015), desenvolvidas predominantemente na Universidade de Coimbra.

O protocolo de registo sistemático da morfologia dentária sugere um conjunto mínimo de caracteres discretos e alguns procedimentos básicos a aplicar em tra- 
balhos académicos focados no estudo paleoantropológico amplo e em relatórios laboratoriais sobre material osteológico de origem arqueológica. Pretende-se sistematizar a recolha de informação em morfologia dentária. Assim, os resultados serão mais completos e comparáveis entre estudos análogos, o que enriquecerá progressivamente o leque de resultados divulgados que são passíveis de auxiliar na compreensão das relações biológicas entre amostras do passado. A aplicação do presente protocolo tem assim o potencial de aumentar as condições de utilização das frequências de morfologia dentária como subsídio do estudo das populações do passado.

\section{Protocolo}

O presente protocolo visa definir as análises-padrão em morfologia dentária. Para esse fim, o protocolo propõe a quantidade mínima de caracteres morfológicos dentários e um conjunto de procedimentos promotores de qualidade na informação. Assim, os resultados poderão ser estatisticamente comparados de modo a analisar a sua afinidade biológica com outras amostras.

\section{Seleção de caracteres discretos dentários}

Neste estudo apenas foram considerados caracteres discretos que fazem parte do Arizona State University Dental
Anthropology System (ASUDAS). Os outros traços morfológicos usados na bibliografia carecem, na sua maioria, de estudos sistemáticos e de registo geograficamente abrangente que permitam aferir apropriadamente a sua utilidade em estudos de populações. O MMPT, ou "mandibular molar pit-tubercle", é um exemplo recentemente revisto (Marado e Silva, 2016). O único carácter discreto considerado nesta recomendação não constante do ASUDAS é a variável discreta recém-descrita "raízes hipotróficas dos incisivos centrais superiores" (RHCIS; "hypotrophic roots of the upper central incisors" [HRUCl] no original), identificado em amostras pré-históricas da Península Ibérica (Figura 1) (Cunha et al., 2012). A inclusão deste carácter justifica-se pela necessidade de continuar a registar a variação morfológica, cronológica e geográfica de âmbito regional das RHCIS. Além deste traço recente, escolheram-se os 27 caracteres discretos dentários do sistema ASUDAS cujo registo foi considerado mais acessível (recorrendo à experiência dos autores), de entre os traços mais variáveis em indivíduos de origem europeia e norte-africana. A designação em língua portuguesa de cada carácter usou a terminologia definida por Marado e colegas (2017a).

\section{Condições de observação}

O aumento da precisão na observação de variáveis morfológicas da dentição é um dos méritos do sistema ASUDAS 
Tabela 1. Lista de caracteres discretos recomendados (e designação no sistema ASUDAS:

Turner et al., 1991) por dente.

\begin{tabular}{|c|c|}
\hline Carácter discreto & Sistema ASUDAS \\
\hline \multicolumn{2}{|c|}{ Incisivo central superior (1IS) } \\
\hline Rotação mesiolingual & Winging \\
\hline Incisivo em pá & Shoveling \\
\hline Cristas labiais marginais & Double-shoveling \\
\hline Proeminências cingulares & Tuberculum dentale \\
\hline Raízes hipotróficas dos incisivos centrais superiores & [Ausente do ASUDAS] \\
\hline \multicolumn{2}{|c|}{ Incisivo lateral superior (2IS) } \\
\hline Incisivos laterais superiores em cavilha & Peg-shaped incisor \\
\hline Sulco lingual & Interruption groove \\
\hline \multicolumn{2}{|c|}{ Canino superior (CS) } \\
\hline Crista mesial defletida & Canine mesial ridge \\
\hline Crista distal acessória & Canine distal accessory ridge \\
\hline \multicolumn{2}{|c|}{ Primeiro pré-molar superior (1PS) } \\
\hline Número de raízes & Premolar root number \\
\hline \multicolumn{2}{|c|}{ Primeiro molar superior (1MS) } \\
\hline Carácter de Carabelli & Carabelli's trait \\
\hline Metacónulo & Cusp 5 (metaconule) \\
\hline \multicolumn{2}{|c|}{ Segundo molar superior (2MS) } \\
\hline Hipocone & Hypocone \\
\hline Número de raízes & Upper molar root number \\
\hline \multicolumn{2}{|c|}{ Terceiro molar superior (3MS) } \\
\hline Agenesia & Congenital absence \\
\hline \multicolumn{2}{|c|}{ Canino inferior $(\mathrm{Cl})$} \\
\hline Número de raízes & Canine root number \\
\hline \multicolumn{2}{|c|}{ Segundo pré-molar inferior (2PI) } \\
\hline Variação das cúspides linguais & Premolar lingual cusp variation \\
\hline \multicolumn{2}{|c|}{ Primeiro molar inferior (1MI) } \\
\hline Fóvea anterior & Anterior fóvea \\
\hline Crista desviada & Deflecting wrinkle \\
\hline Padrão de cúspides & Groove pattern \\
\hline Cúspide 5, hipoconulídeo & Cusp 5 \\
\hline Cúspide 6, entoconulídeo & Cusp 6 \\
\hline Cúspide 7, metaconulídeo & Cusp 7 \\
\hline Protostilídeo & Protostylid \\
\hline \multicolumn{2}{|c|}{ Segundo molar inferior (2MI) } \\
\hline Padrão de cúspides & Groove pattern \\
\hline Cúspide 5, hipoconulídeo & Cusp 5 \\
\hline Número de raízes & Lower molar root number \\
\hline \multicolumn{2}{|c|}{ Terceiro molar inferior (3MI) } \\
\hline Agenesia & Congenital absence \\
\hline
\end{tabular}



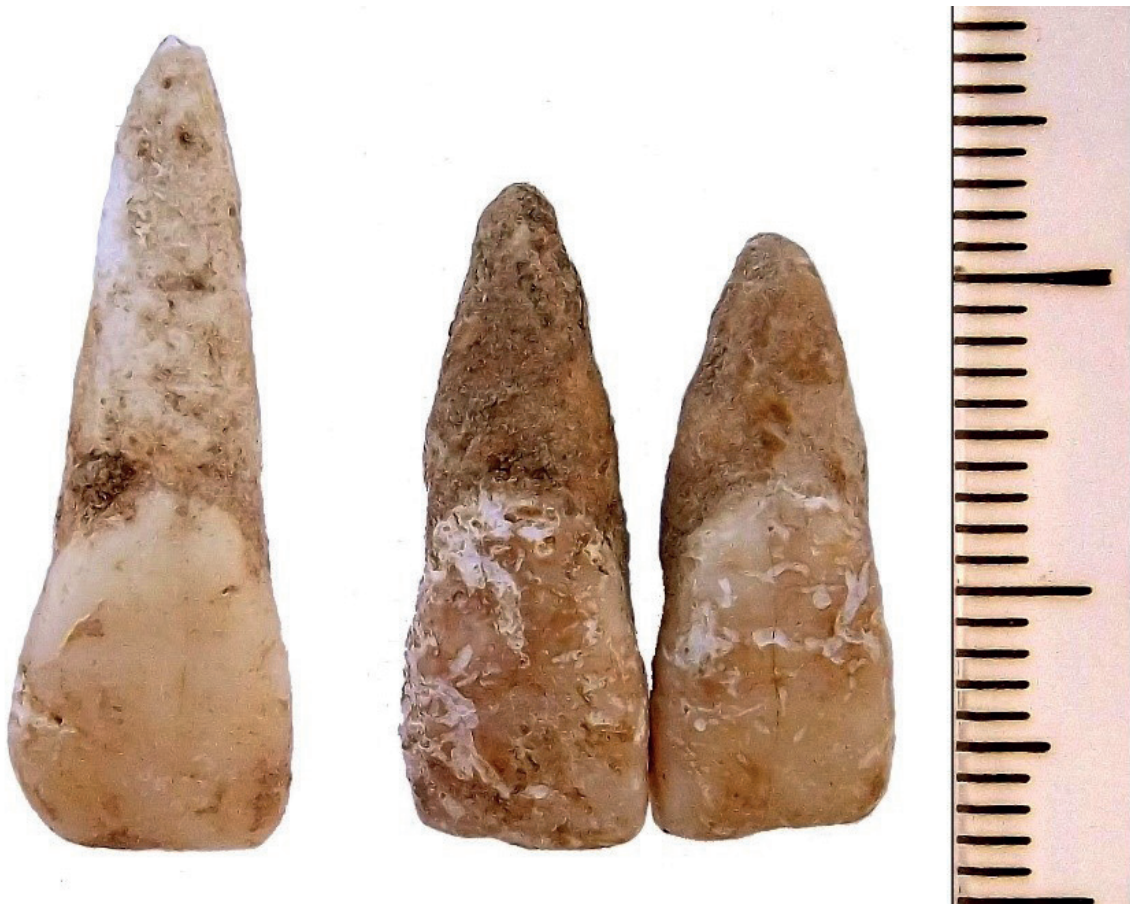

Figura 1. Incisivos centrais superiores (ambos os antímeros) de um indivíduo que apresenta RHICS (incisivo central superior esquerdo, à direita) em oposição a um incisivo central superior direito sem o carácter. Todos provenientes do sítio Calcolítico de Cerro de las Baterías (La Albuera, Espanha). Adaptado de Cunha et al. (2012).

(Hillson, 2005), que deve ser usado na sua plenitude. As observações devem seguir a recomendação do uso de lupa de aumento de 10 vezes e ser acompanhadas da consulta das placas e do texto do sistema ASUDAS (Turner et al., 1991). A visualização adequada requer uma luz forte ou uma lupa com iluminação integrada.

É recomendada a inserção dos dados diretamente em base de dados informatizada, se possível. O uso de fichas de registo em papel implica um processo, evitável e frequentemente demorado, de inserção de dados posterior às fases de observação.

Os períodos diários de observação não devem ser excessivamente prolongados. Idealmente, contemplarão intervalos regulares. O cansaço visual e psicológico pode afetar o constante processo de tomada de decisão. A observação de morfologia dentária exige elevado poder de decisão sobre a possibilidade de observar uma superfície ou sobre qual o grau mais próximo da expressão observada. 


\section{Base de dados}

Uma sugestão de base de dados (concebida em IBM SPSS Statistics v. 23) acompanha o presente artigo. A base de dados contempla o registo de todos os caracteres discretos enumerados em Apêndice e apresentados na Tabela 1, bem como do desgaste oclusal (ver ponto 4. Desgaste e destruição de tecidos), totalizando 88 variáveis. As variáveis listadas na base de dados têm designações que correspondem a abreviação dos nomes dos caracteres discretos em português, seguidas da notação antropológica usada para identificação de cada dente. Esta notação corresponde ao número associado à posição do dente (p. ex.: 1 = primeiro) no campo morfogenético (p. ex:: $M=$ molar), seguido pela arcada dentária $(S=$ superior; I = inferior) e pelo lado (e = esquerdo; $d$ = direito) onde o dente se encontra. Assim, "Desg2PSd" equivale a "desgaste oclusal do segundo pré-molar superior direito".

O registo de todos os caracteres listados (Tabela 1 e Apêndice) e do desgaste em toda a dentição permanente de cada indivíduo devem ser correspondentes a um caso (linha) na base de dados, com registo de todas as variáveis (colunas), permitindo os cálculos estatísticos adequados.

No entanto, qualquer base de dados adotada deve corresponder às características gerais do material fornecido. Nomeadamente, numa amostra de dentes soltos pode-se abreviar o número de variáveis (colunas da tabela de inserção de dados) ao remover a repetição da observação de cada carácter para ambos os lados. Para tal, bastaria adicionar uma variável de identificação do lado ou do dente. O número de entradas (linhas da tabela dos dados) aumentaria. Salienta-se que esta opção não é adequada para o estudo de dentes que se saiba pertencerem ao mesmo indivíduo, por dificultar o cálculo de correlações entre os caracteres (ver ponto 7. Correlação) e de assimetria (ver Marado et al., 2017b).

\section{Desgaste e destruição de tecidos}

O desgaste corresponde à perda progressiva de tecidos dentários (esmalte e dentina) por contacto com outros dentes e substâncias (como a comida). Este fenómeno é uma função normal da dentição (Kieser et al., 2001; Hillson, 2005; Soames e Southam, 2005; Kaidonis, 2008) que pode, ainda assim, causar complicações resultantes em patologias dentárias se atingir níveis elevados (exemplos citados em Wasterlain, 2006). Os processos que explicam perda de tecidos dentários são o atrito, a abrasão, a erosão e a abfração. $O$ atrito corresponde ao contacto entre os dentes. A abrasão define-se pelo contacto dos dentes com comida, tecidos moles e outros objetos de origem externa. A erosão decorre através da exposição dos dentes a ambiente ácido, devido à consequente dissolução química. Finalmente, abfração é a destruição de esmalte cervical (junto à linha cimento-esmalte) pela 
combinação de força tênsil e ambiente ácido (Kieser et al., 2001; Hillson, 2005; Soames e Southam, 2005; Kaidonis, 2008).

Recomenda-se o registo do desgaste oclusal em toda a dentição, recorrendo

\section{oclusal é meramente indicativo, já que al-} guns mecanismos de desgaste permitem a obliteração de áreas específicas em processos independentes do ritmo de desgaste oclusal. Os diversos usos da dentição como ferramenta ou como terceira mão são exemplo de comportamentos que originam padrões particulares de desgaste ( $p$. ex.: Irish e Turner, 1997; Scott e Jolie, 2008).

O desgaste tem influência sobre as frequências de alguns caracteres discretos, devendo preferivelmente evitar-se a comparação de amostras que apresentem médias de desgaste oclusal muito divergentes (Burnett et al., 2013; Marado, 2014). Salienta-se, ainda assim, que o prejuízo que o desgaste ocasiona é ultrapassável. Esta conclusão é demonstrada pelo sucesso da subárea da morfologia dentária em identificar padrões de variação biológica corroborados por outras áreas científicas (Burnett et al., 2013). O cuidado no registo de superfícies que não tenham sido alteradas assume um papel central nesse sucesso, juntamente com a experiência de observação.

Conforme devidamente anotado no sistema ASUDAS (Turner et al., 1991), muitos caracteres discretos não devem ser observados quando o dente apresenta elevado desgaste na área correspondente. As superfícies a observar podem ainda apresentar outros obstáculos à sua observação, de origem patológica (cáries, tártaro, fraturas traumáticas, etc.) ou tafonómica (fraturas post mortem, congregações superficiais, erosão diagenética, etc.) (Hillson, 2005). Um carácter deve ser considerado não observável sempre que o desgaste ou alterações patológicas/tafonómicas ponham em causa a qualidade da observação e, consequentemente, a sua reprodutibilidade. É preferível diminuir a quantidade da amostra por exercer cautela na observação do que diminuir a qualidade dos resultados e de consequentes cálculos de afinidade biológica.

\section{Erro intraobservador}

O erro (ou consistência) intraobservador é um indicador importante na divulgação de dados de morfologia dentária, uma vez que a subjetividade é inerente ao seu registo devido à natureza quase contínua da sua variação (Scott e Turner, 1997; Hillson, 2005). É recomendável, sempre que o tempo o permita, a realização de duas observações completas da amostra. Uma das observações pode ser parcial, no caso de amostras com centenas de indivíduos, ou superiores a vários milhares de dentes.

O cálculo do erro interobservador é útil na comparação entre dados recolhi- 
dos por diferentes investigadores e na perceção da qualidade de registo de um investigador inexperiente em comparação com outro, idealmente mais experiente (ver Nichol e Turner, 1986). Se possível, o cálculo do erro interobservador é aconselhado. No entanto, os constrangimentos temporais tornam difícil a disponibilidade de dados comparativos fornecidos por investigadores experientes. Por outro lado, se o investigador inexperiente tiver sido devidamente treinado e seguir o texto e as placas ASUDAS, bem como indicações complementares, o erro intraobservador é suficientemente informativo em relação à qualidade da observação desse investigador. Assim, o cálculo do erro interobservador pode ser dispensado na aplicação do presente protocolo.

No cálculo do erro intraobservador, idealmente devem ser realizadas três observações, se o observador for inexperiente; a primeira destas observações servirá para prática do observador e, possivelmente, para registo do seu progresso (Marado, 2017a). Apenas a observação final deve ser considerada nos resultados para aferição de afinidade biológica.

Recomenda-se o cálculo da percentagem de consistência entre observações. Outros testes estatísticos complementares podem ser calculados. Porém a percentagem de consistência é de simples interpretação e facilidade de cálculo, além de transmitir a informação essencial e ser passível de adaptação. A percentagem de consistência deve ser calculada para cada carácter a partir dos resultados de duas observações. Sempre que uma variável (determinado carácter em determinado dente) é avaliada com o mesmo grau de expressão nas duas observações, o resultado é considerado concordante. Sempre que a mesma variável é avaliada com diferentes graus em cada observação, é considerado discordante. A percentagem de consistência (c\%) encontra-se através da divisão dos resultados concordantes (C) pela soma dos resultados concordantes (C) com os resultados discordantes (D), e posterior multiplicação por 100:

$$
c \%=\left(\frac{C}{C+D}\right) \times 100
$$

A percentagem de consistência pode ser adaptada de modo a considerar discordantes apenas observações que divirjam mais do que um grau ou divirjam na identificação de presença ou ausência do carácter observado. Estes cálculos alternativos são informativos por permitirem percecionar a dimensão e o impacto da inconsistência entre observações (ver Nichol e Turner, 1986; Marado, 2014; 2017).

É igualmente útil verificar a consistência na identificação de caracteres como observáveis ou não. O cálculo da percentagem de consistência de identificação de caracteres observáveis utiliza a fórmula apresentada acima. Um resultado é concordante sempre que seja considerado observável ou não observável em ambas as observações. Assim, é considerado discordante quando numa das observações é observado, e na outra não é. 
Os valores expetáveis de consistência e alguns cálculos estatísticos relacionados com o erro intraobservador são reportados por Nichol e Turner (1986) e por Marado (2014; 2017), por exemplo.

\section{Método de contagem}

O método de contagem individual é recomendado para o cálculo de frequências, por permitir a mais adequada representação de cada perfil genético subjacente à variação fenética observada. O método de contagem individual contabiliza apenas um dente para cada carácter discreto observado em cada indivíduo. Para tal, seleciona-se em cada indivíduo o dente do lado que apresenta maior expressão do carácter. Assim, o dente com grau mais elevado é usado na definição da frequência de cada carácter (para descrições mais pormenorizadas dos métodos de contagem, veja-se Scott e Turner, 1997).

Este método de contagem não pode ser aplicado em amostras quase exclusivamente compostas por dentes soltos. As amostras provenientes de contextos múltiplos ou coletivos podem ser sujeitas a condições tafonómicas específicas que impedem a identificação de um número estatisticamente viável de indivíduos. Contudo, a análise estatística pode ser aplicada com sucesso se for realizada a contagem por lado: seleção do antímero (lado) que apresenta maior frequência, considerando apenas o lado esquerdo ou direito em cada carácter (ver, p. ex.: Cunha, 2015).

A frequência de cada carácter não-métrico deve ser reportada por grau de variação (p. ex:: Scott et al., 2013; Marado, 2014), como exemplificado na Tabela 2.

Tabela 2. Distribuição de frequências por grau de expressão da cúspide 5 (hipoconulídeo) no primeiro molar inferior (contagem por dente) na série de mandíbulas do Museu de História Natural da Universidade do Porto (Marado 2010; 2012).

\begin{tabular}{lcc}
\hline Grau & Percentagem & $\boldsymbol{n}$ \\
\hline $\mathbf{0}$ & 4,3 & 4 \\
\hline $\mathbf{1}$ & 0,0 & 0 \\
\hline $\mathbf{2}$ & 4,3 & 4 \\
\hline $\mathbf{3}$ & 13,8 & 13 \\
\hline $\mathbf{4}$ & 33,0 & 31 \\
\hline $\mathbf{5}$ & $\mathbf{4 4 , 7}$ & 42 \\
\hline Presença (graus 1 a 5) & 95,7 & 90 \\
\hline Total & 100,0 & 94 \\
\hline
\end{tabular}


Divulgar apenas a frequência de presença ou de ausência condiciona as opções dos investigadores na definição do ponto de corte de cada carácter. O ponto de corte é o grau a partir do qual um carácter é considerado presente. Tendo acesso à frequência por grau, qualquer investigador poderá adaptar o ponto de corte à sua necessidade. Note-se a ocorrência na literatura de frequências do mesmo carácter no mesmo dente que não são comparáveis pelo uso de pontos de corte diferentes (p. ex:: carácter de Carabelli em Scott e Turner [1997] e Hanihara [2008]).

\section{Correlação}

Os dentes focais de cada carácter (peças dentárias que expressam mais consistentemente o carácter e permitem obter o máximo de informação) serão os únicos sugeridos para observação na maioria dos caracteres (Tabela 1). Evitam-se dessa forma os caracteres correlacionados, como podem ser os que se repetem ao longo de um campo dentário, em todos os incisivos, pré-molares ou molares. 0 cálculo da afinidade ou distância fenética entre populações não permite o uso de caracteres correlacionados, já que as correlações entre as variáveis enviesam os dados obtidos por testes estatísticos como o MMD ("mean measure of divergence", ou medida média da divergência) (Irish, 2010).

O teste do nível de correlação entre todos os caracteres incluídos deve ser sempre avaliado antes do cálculo de afini- dade biológica. O coeficiente de correlação tau-b de Kendall ("Kendall's tau-b rank correlation coeficiente") deve ser usado para comparar cada variável (carácter não-métrico dentário) com todas as outras. As correlações são consideradas moderadas se o tau $(\tau)$ for superior a 0,3 ou inferior a $-0,3$. As correlações fortes apresentam $\tau$ superior a 0,5 ou inferior a -0,5. Este teste estatístico permite compreender se os caracteres discretos são independentes na amostra. Para tal, usa a ordenação da expressão de cada carácter na amostra para revelar se o aumento de expressão de um carácter é consistentemente acompanhado do aumento (ou diminuição) da expressão do outro carácter.

\section{Cálculo de afinidade biológica}

A afinidade biológica pode ser calculada estatisticamente, com base nas frequências dos caracteres discretos observados, através de diversos métodos. A revisão metodológica da estatística em morfologia dentária ultrapassa o escopo do presente texto, tendo sido abordada por outros autores (Edgar, 2004; Harris, 2008; Irish, 2010).

Os métodos mais utilizados são o MMD ("mean measure of divergence", ou medida média da divergência) e o PCA ("principal components analysis", ou análise de componentes principais).

O MMD determina a medição da distância biológica entre populações derivada da divergência entre as frequências 
médias de diversos caracteres discretos medidos nessas populações (Tyrrell, 2000). Para visualizar os resultados, é necessário o cálculo do MDS ("multidimensional scaling", ou escalamento multidimensional) (ver Vargiu et al., 2009).

Já o PCA identifica os padrões de distribuição das frequências e traduz a variação presente entre as amostras em eixos, reduzindo a dimensão da variação para que possa ser visualizada graficamente (Irish e Guatelli-Steinberg, 2003; Delgado-Burbano, 2007; Harris, 2008).

A aplicação do MMD foi explicada em pormenor por Sołtysiak (2011), através da aplicação estatística R. O seguimento dos passos descritos permite o cálculo desta estatística com facilidade. Porém, é necessária alguma adaptação. O Microsoft Excel em língua portuguesa (contrariamente à versão inglesa do programa) gera os ficheiros CSV ("comma separated values", ou valores separados por vírgula) pedidos no artigo com os valores separados por ponto e vírgula (;). Isto deve-se ao facto de em língua portuguesa as unidades serem separadas das frações por vírgulas, e não por pontos. Assim, os utilizadores devem alterar (no programa Bloco de Notas do sistema operativo Microsoft Windows, por exemplo) os ficheiros CSV. Devem usar a função de substituição automática de todas vírgulas (,) por pontos (.), e de todos os pontos e vírgulas (;) por vírgulas (,). Depois dessa alteração, o script fornecido por Sołtysiak (2011) funciona normalmente.

A aplicação do PCA foi também ex- plicada em detalhe por Marado (2017b), recorrendo ao programa IBM SPSS. Recorrendo ao artigo (em português), o cálculo e interpretação deste método quantitativo é acessível a pessoas com escassa formação académica na área da estatística.

\section{Apêndice:}

\section{Caracteres morfológicos selecionados}

Rotação mesiolingual (Winging; 11S) - É possível identificar a rotação mesiolingual nos incisivos centrais através dos alvéolos, quando os dentes estão ausentes, porque esta rotação ocorre ao nível radicular (Scott et al., 2016). Scott e Turner recomendam, no entanto, que este carácter apenas seja registado quando ambos os incisivos centrais se encontrem in situ (Scott e Turner, 1997).

Incisivo em pá (Shoveling; 1IS) (Figura 2) Turner e colegas (1991) recomendam especificamente o uso de apenas um dente, devido às correlações habituais com os incisivos laterais e caninos. Scott e Turner (1997) informam que é possível, mas pouco útil, caracterizar cada margem independentemente.

Cristas labiais marginais (Double-shoveling; 1IS) - É mais comum e expressivo no incisivo central superior, podendo ser mais expressivo na margem mesial (Scott e Turner, 1997). No caso de o dente estar fortemente desgastado só pode ser registado com segurança se se tratar de um grau 6 ou superior (Turner et al., 1991). 


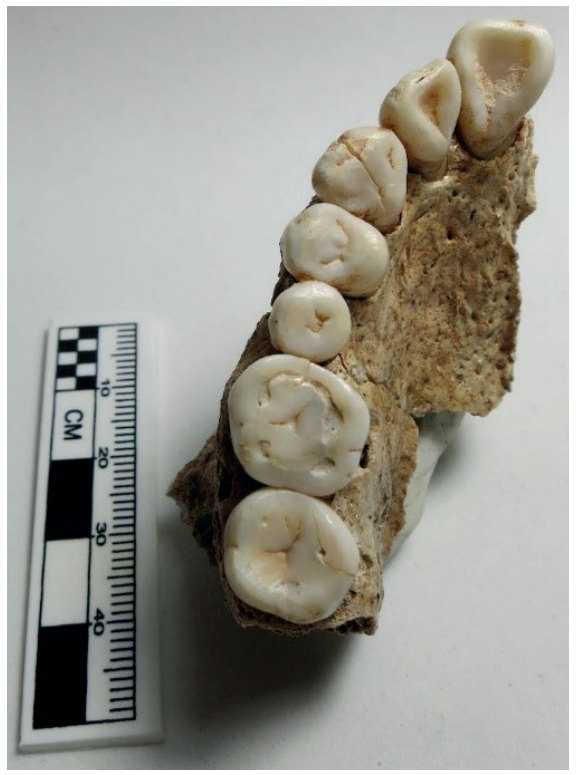

Figura 2. Fragmento maxilar direito com incisivos, pré-molares, primeiro e segundo molar de indivíduo ameríndio proveniente do sítio Colonial (século XVI-XVII) do Rosário dos Homens Brancos, Belém, Pará, Brasil. Apresenta incisivos (central e lateral direitos) em pá de grau 4 (ICS) e 5 (ILS). Note-se ainda: (a) rotação mesiolingual não passível de registo por ausência do ICS esquerdo, (b) ausência (grau 0) de proeminências cingulares no ICS, (c) ausência (grau 0) de ILS em cavilha, (d) ausência (grau 0) de crista mesial defletida no CS, (e) crista distal acessória não observável devido a desgaste no CS, (f) metacónulo não observável devido a desgaste oclusal no 1MS, (g) hipocone de grau 3,5 no 2MS, e (h) agenesia ou presença do $3 \mathrm{MS}$ não observável devido a destruição post mortem do osso alveolar.

Proeminências cingulares (Tuberculum dentale; 1IS) - Turner e colegas (1991) avisam que não há sistema de registo satisfatório, incluindo o seu próprio, para este carácter. Devido à variação morfológica, em diversos graus, de cristas e tubérculos (Turner et al., 1991; Scott e Turner, 1997), foi verificada uma grande margem de erro por Nichol e Turner (1986) e por Marado (2014; 2017). Devido a este fator, sugerimos a observação de proeminências cingulares no incisivo central em vez de no lateral, tal como é recomendado no sistema ASUDAS.

\section{Raízes hipotróficas dos incisivos cen-} trais superiores (Hypotrophic roots of the upper central incisors; 1IS) - As raízes hipotróficas identificam-se quando o comprimento da raiz é igual ou menor do que a altura máxima da coroa dos incisivos centrais superiores (Figura 1), sendo a norma anatómica do rácio entre a raiz e a coroa igual a 1,5:1 (a raiz tem normalmente o comprimento de 1,5 vezes o comprimento da coroa). As medidas devem ser recolhidas em vista labial com um paquímetro (ou craveira). A raiz é medida desde o seu ápice até ao ponto sagital da junção cimento-esmalte do incisivo. A coroa é medida desde este último ponto (ponto sagital da junção cimento-esmalte do incisivo) até ao ponto mais oclusal do bordo incisal (Cunha et al., 2012).

\section{Incisivos laterais superiores em cavilha}

(Peg-shaped incisor; 2IS) - Os incisivos laterais maxilares são os mais variáveis em tamanho, o que pode culminar na ausência congénita do dente (Turner et al., 1991; Scott e Turner, 1997). 
Sulco lingual (Interruption grooves; 2IS) -

Por ser mais expressivo nesse dente (Turner et al., 1991), é recomendada a observação no incisivo lateral superior em estudos de populações, apesar de também poder manifestar-se no incisivo central (Scott e Turner, 1997).

Crista mesial defletida (Canine mesial ridge; CS) - Carácter sempre associado a tuberculum dentale e frequentemente assimétrico, que é característico de africanos subsaarianos, particularmente bosquímanos, mas que pode estar presente noutras populações (Turner et al., 1991; Scott e Turner, 1997). Irish e Morris (1996) recomendam cuidado no registo, já que é comum a identi- ficação errónea deste carácter, muito raro em populações que não as africanas subsaarianas. Os autores recomendam que o registo seja sempre acompanhado da leitura das indicações fornecidas em Turner e colegas (1991).

Crista distal acessória (Canine distal accessory ridge; (S) - Carácter que só deve ser observado com pouco desgaste e está muito sujeito a dimorfismo sexual, principalmente no canino inferior (Scott e Turner, 1997; Marado, 2014).

Número de raízes (Premolar root number; 1PS) (Figura 3) - Quando o dente se perdeu post mortem, o número de raízes pode ser avaliado através dos alvéolos; se estiver in situ, regista-se

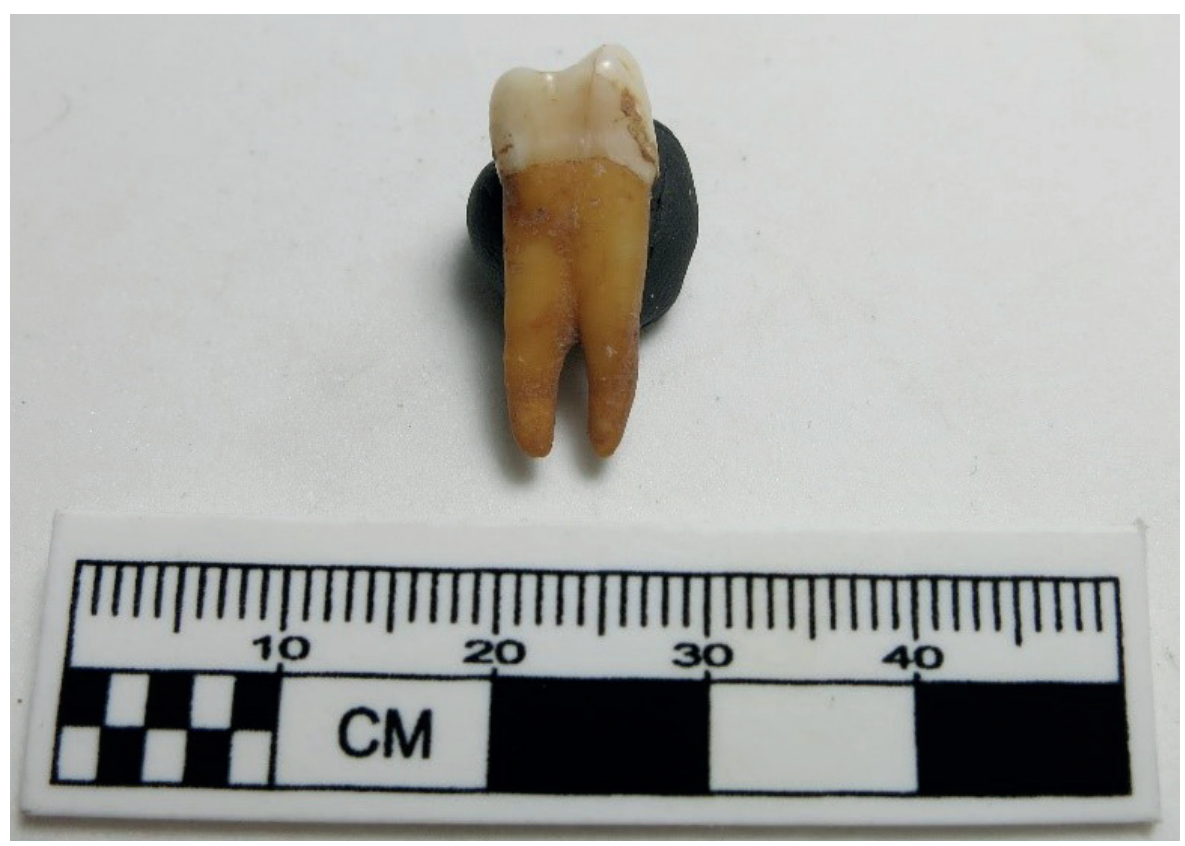

Figura 3. 1PS apresentando raízes duplas em indivíduo de etnia desconhecida, proveniente do sítio Colonial (século XVI-XVII) do Rosário dos Homens Brancos, Belém, Pará, Brasil. 
levantando cuidadosamente o dente de modo a verificar a divisão radicular (pode usar-se uma pequena lanterna para auxiliar; ver Turner et al., 1991).

Carácter de Carabelli (Carabelli's trait; 1MS) - Dente focal identificado por Scott e Turner (1997).

Metacónulo (Metaconule; 1MS) - É mais raro no segundo molar superior e diffcil de registar no terceiro molar na presença de desgaste (Turner et al., 1991).

Hipocone (Hypocone; 2MS) - Ocasionalmente ocorre redução da cúspide distolingual em molares superiores, mas principalmente no segundo molar (Turner et al., 1991; Scott e Turner, 1997).

Número de raízes (2MS) - A maior variação surge no segundo molar superior, já que normalmente o primeiro tem três raízes e o terceiro tem uma ou duas; pode ser observado através do alvéolo, na ausência do dente (Turner et al., 1991; Scott e Turner, 1997).

Agenesia (Congenital absence; 3MS, 3MI) - A ausência de raios-X, por questões de custos e tempo (Turner et al., 1991), não permite que os resultados sejam fidedignos; porém, a margem de erro é mínima (de acordo com observação pessoal).

Número de raízes (Canine root number; Cl) - Raiz supranumerária, normalmente lingual e mais estreita, separada num mínimo de um quarto do tamanho total da raiz (Turner et al., 1991; Scott e Turner, 1997). É observável no alvéolo, se o dente estiver ausente.
Variação das cúspides linguais (Premolar lingual cusp variation; 2PI) - O segundo pré-molar inferior apresenta maior frequência e é mais fácil de registar que o primeiro (Turner et al., 1991; Scott e Turner, 1997).

Fóvea anterior (Anterior fovea; $1 \mathrm{MI}$ ) - É comummente reportado; deve ser registado com cuidado, devido a ser frequentemente difícil identificar em dentes com desgaste acentuado (Turner et al., 1991).

Crista desviada (Deflecting wrinkle; $1 \mathrm{MI}$ ) Os restantes molares inferiores muito raramente apresentam o carácter; o desgaste afeta facilmente o registo (Turner et al., 1991; Scott e Turner, 1997).

Padrão de cúspides (Groove pattern; 1MI, 2MI) - Apesar de o dente focal ser o segundo molar inferior (Figura 4), os autores recomendam o registo do primeiro e segundo molares, se possível (Turner et al., 1991; Scott e Turner, 1997), como habitual.

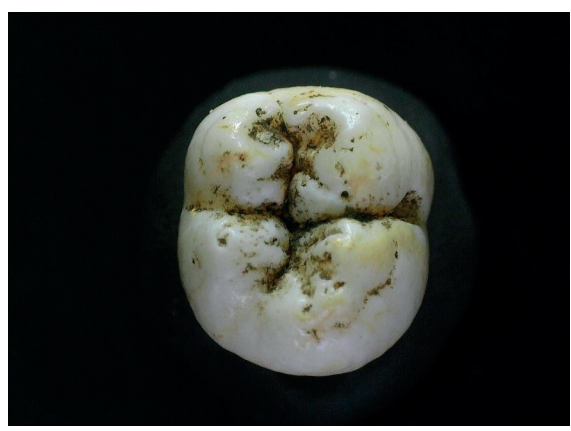

Figura 4. 2Ml direito apresentando o padrão de cúspides X. Indivíduo juvenil pré-colonial, proveniente do Sítio Sucurijú, Amazonas, Brasil. 
Cúspide 5, hipoconulídeo (Cusp 5; 1MI, 2MI) - Substitui a determinação do número de cúspides, cuja descrição por Scott e Turner (1997) menciona a placa da C5 (de Turner et al., 1991).

Cúspide 6, entoconulídeo (Cusp 6; 1MI) - A ausência habitual da C5 no segundo molar inferior (Scott e Turner, 1997) e a conhecida variabilidade do terceiro justificam o dente focal.

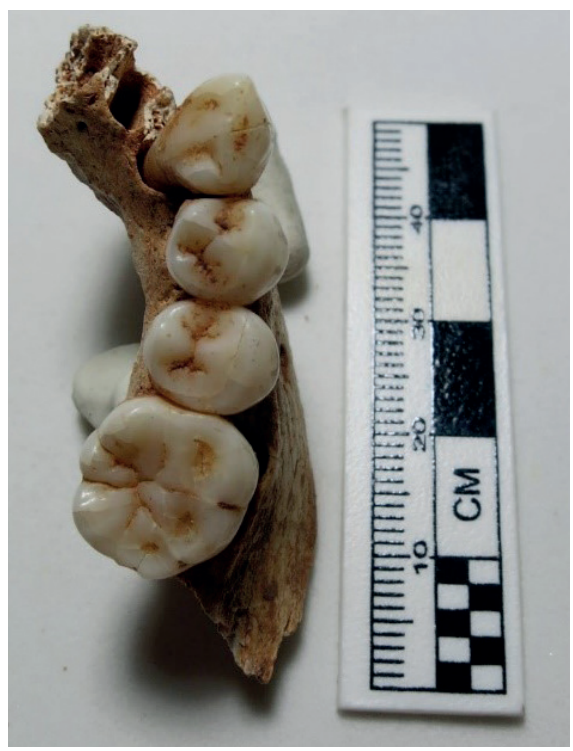

Figura 5. Fragmento mandibular direito com canino, pré-molares e primeiro molar de indivíduo de etnia desconhecida, proveniente do sítio Colonial (século XVI-XVII) do Rosário dos Homens Brancos, Belém, Pará, Brasil. O $1 \mathrm{Ml}$ apresenta metaconulídeo (C7) de grau 4. Note-se ainda: (a) grau 0 da variação das cúspides linguais do 4PI, (b) fóvea anterior não observável devido ao desgaste oclusal no 1Ml, (c) crista desviada não observável devido ao desgaste oclusal no $1 \mathrm{Ml}$, (d) padrão de cúspides $Y$ no 1MI, (e) grau 5 do hipoconulídeo no 1MI e (f) ausência (grau 0) de entoconulídeo no 1MI.
Cúspide 7, metaconulídeo (Cusp 7; 1MI)

(Figura 5) - Dente focal sugerido por Scott e Turner (1997).

Protostilídeo (Protostylid; 1MI) - O dente focal é sugerido por Scott e Turner (1997), por surgir aí com maior frequência. $O$ grau de expressão pode ser superior em $2 \mathrm{Ml}$ e $3 \mathrm{Ml}$.

\section{Número de raízes do molar inferior} (Lower molar root number; 2MI) - Uma terceira raiz, supranumerária, é mais comum nos primeiros molares inferiores; a presença atípica de uma única raiz é comum no terceiro molar, mas tem como dente focal o segundo (Scott e Turner, 1997). Pode ser observado mesmo com perda dentária post mortem, através do alvéolo.

\section{Referências bibliográficas}

Alt, K. W.; Vach, W. 1998. Kinship studies in skeletal remains - concepts and examples. In: Alt, K. W.; Rösing, F. W.; Teschler-Nicola, M. (eds.) Dental anthropology: fundamentals, limits, and prospects. Viena, Springer: 537-554.

Burnett, S. E.; Irish, J. D.; Fong, M. R. 2013. Wear's the problem? Examining the effect of dental wear on studies of crown morphology. In: Scott, G. R.; Irish, J. D. (eds.) Anthropological perspectives on dental morphology: genetics, evolution, variation. New York, Cambridge University Press: 535-554. DOI: 10.1017/ CBO9780511984464.021. 
Coelho, L. J. G. 2013. Miranda dapar de Podentes: Estudo paleobiológico de um ossário exumado junto à Torre Sineira em Miranda do Corvo. Dissertação de Mestrado em Evolução Humana, Departamento de Ciências da Vida, Faculdade de Ciências e Tecnologia, Universidade de Coimbra.

Costa, P. B. 2006. Diagnósticos do passado: Estudo paleobiológico de um ossário proveniente do antigo cemitério do Hospital de Santo António do Porto. Dissertação de Licenciatura em Antropologia, Departamento de Antropologia, Faculdade de Ciências e Tecnologia, Universidade de Coimbra.

Costa, T. M. D. 2007. Vidas passadas, memórias futuras: contribuição para o estudo paleobiológico de um ossário proveniente dos jardins do Hospital de Santo António do Porto. Dissertação de Licenciatura em Antropologia, Departamento de Antropologia, Faculdade de Ciências e Tecnologia, Universidade de Coimbra.

Cunha, C. M. S. 2015. Crossing the river: the dental morphology of Chalcolithic populations in the Middle Guadiana. Tese de Doutoramento em Antropologia, Universidade de Coimbra.

Cunha, C.; Silva, A. M.; Irish, J.; Scott, G. R.; Tomé, T.; Marquéz, J. 2012. Hypotrophic roots of the upper central incisors - a proposed new discrete dental trait. Dental Anthropology, 25 (1): 8-14.

Cunha, H. 2011. Mértola: no caminho do passado. Dissertação de Licenciatura em Antropologia, Departamento de Antropologia, Faculdade de Ciências e Tecnologia, Universidade de Coimbra.
Delgado-Burbano, M. E. 2007. Population affinities of African Colombians to SubSaharan Africans based on dental morphology. HOMO - Journal of Comparative Human Biology, 58: 329-356.

Edgar, H. J. H. 2004. Dentitions, Distance, and Difficulty: A Comparison of Two Statistical Techniques for Dental Morphological Data. Dental Anthropology, 17 (2): 5562.

Fernandes, I. A. T. N. 2006. A voz da cegonha: Análise paleobiológica de uma amostra de esqueletos e ossário associado, provenientes da necrópole romana do Monte da Cegonha, Vidigueira. Dissertação de Licenciatura em Antropologia, Departamento de Antropologia, Faculdade de Ciências e Tecnologia, Universidade de Coimbra

Godinho, R. M. 2008. Vestígios de um Império passado: A necrópole do Colégio de Santo Antão-o-Novo e a Lisboa dos séculos XVI-XVIII. Dissertação de Mestrado em Evolução Humana, Departamento de Antropologia, Faculdade de Ciências e Tecnologia, Universidade de Coimbra.

Gomes, T. A. S. 2005. Murmúrios medievais de Santarém: Análise antropológica de uma amostra da Necrópole medieval da Rua dos Barcos, Ribeira de Santarém. Dissertação de Licenciatura em Antropologia, Departamento de Antropologia, Faculdade de Ciências e Tecnologia, Universidade de Coimbra.

Gonçalves, C. 2010. Ao Largo de Santarém... Estudo de uma amostra osteológica humana exumada no Largo Cândido dos Reis, 
Santarém (XVI-XVIII). Dissertação de Mestrado em Evolução Humana, Departamento de Ciências da Vida, Faculdade de Ciências e Tecnologia, Universidade de Coimbra.

Graça, V. P. C. 2010. Scallabis no alvorecer da Modernidade. Análise paleobiológica de uma amostra osteológica humana exumada no Largo Cândido dos Reis (Santarém). Dissertação de Mestrado em Evolução Humana, Departamento de Ciências da Vida, Faculdade de Ciências e Tecnologia, Universidade de Coimbra.

Hanihara, T. 2008. Morphological variation of major human populations based on nonmetric dental traits. American Journal of Physical Anthropology, 136(2): 169182. DOl: 10.1002/ajpa.20792.

Harris, E. F. 2008. Statistical applications in dental anthropology. In: Irish, J. D.; Nelson, G. C. (eds.) Technique and application in dental anthropology. New York, Cambridge University Press: 35-68. DOI: 10.1017/CBO9780511542442.003.

Hillson, S. 2005. Teeth. 2nd edition. New York, Cambridge University Press. DOI: 10.1017/CBO9780511614477.

Hughes, T. E.; Townsend, G. C. 2013. Twin and family studies of human dental crown morphology: Genetic, epigenetic, and environmental determinants of the modern human dentition. In: Scott, G. R.; Irish, J. D. (eds.) Anthropological perspectives on dental morphology: genetics, evolution, variation. New York, Cambridge University Press: 31-68. DOI: 10.1017/CBO9780511984464.003.
Irish, J. D. 1993. Biological Affinities of Late Pleistocene through Modern African Aboriginal Populations: the Dental Evidence. Doctoral dissertation, Arizona State University. Irish, J. D. 1998. Dental morphological affinities of Late Pleistocene through recent sub-Saharan and North African peoples. Bulletins et Mémoires de la Société d'anthropologie de Paris, [Nouvelle Série] 10 (3-4): 237-272.

Irish, J. D. 2010. The Mean Measure of Divergence: Its utility in model-free and model-bound analyses relative to the Mahalanobis $D^{2}$ distance for nonmetric traits. American Journal of Human Biology, 22(3): 378-395. DOI: 10.1002/ ajhb.21010.

Irish, J. D.; Guatelli-Steinberg, D. 2003. Ancient teeth and modern human origins: An expanded comparison of African PlioPleistocene and recent world dental samples. Journal of Human Evolution, 45(2): 113-144. DOI: 10.1016/S00472484(03)00090-3.

Irish, J. D.; Morris, D. H. 1996. Technical note: Canine Mesial Ridge (Bushman canine) dental trait definition. American Journal of Physical Anthropology, 99(2): 357-359. DOI: 10.1002/ajpa.1330990202.

Irish, J. D.; Turner, C. G. II. 1997. First Evidence of LSAMAT in Non-Native Americans: Historic Senegalese from West Africa. American Journal of Physical Anthropology, 102(1): 141-146. DOI: 10.1002/ (SICI)1096-8644(199701)102:1<141::AIDAJPA12>3.0.CO;2-0.

Jackes, M.; Lubell, D.; Meiklejohn, C. 1997. Healthy but mortal: Human biology 
and the first farmers of Western Europe. Antiquity, 71: 639-658. DOI: 10.1017/ S0003598X00085379.

Jackes, M.; Silva, A. M.; Irish, J. 2001. Dental morphology: A valuable contribution to our understanding of prehistory. Journal of Iberian Archaeology, 3: 97-119.

Jesus, C. C. 2012. Museu Nacional Machado de Castro: Resquícios duma Coimbra Medieval. Estudo paleobiológico de uma amostra exumada da antiga igreja românica de S. João de Almedina. Dissertação de Mestrado em Evolução Humana, Departamento de Ciências da Vida, Faculdade de Ciências e Tecnologia, Universidade de Coimbra.

Kaidonis, J. A. 2008. Tooth wear: the view of the anthropologist. Clinical Oral Investigations, 12(S1): S21-S26. DOI: 10.1007/ s00784-007-0154-8.

Kieser, J. A.; Dennison, K. J.; Kaidonis, J. A.; Huang, D.; Herbison, P. G. P; Tayles, N. G. 2001. Patterns of Dental Wear in the Early Maori Dentition. International Journal of Osteoarchaeology, 11: 206-217. DOI: 10.1002/oa.563.

Leandro, I. R. R. 2011. Mértola: Testemunhos de um passado medieval. Estudo paleobiológico de 30 esqueletos provenientes da Alcáçova do Castelo de Mértola. Dissertação de Mestrado em Evolução Humana, Departamento de Ciências da Vida, Faculdade de Ciências e Tecnologia, Universidade de Coimbra.

Lucas, M. 2006. A necrópole de Cerro da Vila, em Vilamoura: Análise antropológica dos indivíduos exumados. Dissertação de
Licenciatura em Antropologia, Departamento de Antropologia, Faculdade de Ciências e Tecnologia, Universidade de Coimbra.

Lukacs, J. R.; Kuswandari, S. 2013. Crown morphology of Malay deciduous teeth: Trait frequencies and biological affinities. In: Scott, G. R.; Irish, J. D. (eds.) Anthropological perspectives on dental morphology: genetics, evolution, variation. New York, Cambridge University Press: 453-478. DOI: 10.1017/CBO9780511984464.018.

Manabe, Y.; Oyamada, J.; Kitagawa, Y.; Igawa, K.; Kato, K.; Matsushita, T.; Rokutanda, A. 2011. Nonmetric dental characteristics of the Early Modern population of Okinawa Island in Nansei Islands, Japan. International Journal of Osteoarchaeology, 21(6): 679-693. DOI: 10.1002/oa.1174.

Marado, L. M. 2010. Análise dos caracteres discretos da dentição inferior e do osso mandibular numa série do Museu de História Natural (FCUP). Dissertação de Mestrado em Evolução Humana, Departamento de Ciências da Vida, Faculdade de Ciências e Tecnologia, Universidade de Coimbra.

Marado, L. M. 2012. The value of dental morphology in the archaeological context: Example of a Portuguese population from the late 19th and early 20th centuries. In: Cascalheira, J.; Gonçalves, C. (eds.) Actas das IV Jornadas de Jovens em Investigação Arqueológica - JIA 2011, Vol. I, 11 a 13 de Maio, 2011. Faro, Universidade do Algarve: 109-114.

Marado, L. M. 2014. Characterization of the dental morphology of a Portuguese sample 
from the $19^{\text {th }}$ and $20^{\text {th }}$ centuries. Tese de Doutoramento em Antropologia, Universidade de Coimbra.

Marado, L. M. 2017a. Dental nonmetric trait intraobserver precision: three observa-

Marado, L. M. 2017b. Estimativa de afinidade biológica em morfologia dentária: aplicar e interpretar o PCA em SPSS. Cadernos do GEEvH [Aceite em 3/01/2017].

Marado, L. M.; Silva, A. M. 2016. The mandibular molar pit-tubercle (MMPT) dental nonmetric trait: comprehensive analysis of a large sample. HOMO - Journal of Comparative Human Biology, 67(6): 462-470. DOI: 10.1016/j.jchb.2016.09.003.

Marado, L. M.; Silva, A. M. 2017. Dental and oral nonmetric traits in a Coimbra reference sample: testing intrasample chronological and spatial variation. Archaeological and Anthropological Sciences. Published online: 19 December 2016. DOI: 10.1007/ s12520-016-0455-4.

Marado, L. M.; Cunha, C.; Silva, A. M. 2017 a. Glossário de morfologia dentária Tradução para português da terminologia usada em inglês. Antropologia Portuguesa, 32/33: 77-96. DOI: http://doi. org/10.14195/2182-7982_32_5.

Marado, L. M.; Silva, A. M.; Irish, J. D. 2017b. Fluctuating asymmetry in dental and mandibular nonmetric traits as evidence for childcare sex bias in 19th/20th century Portugal. HOMO - Journal of Comparative Human Biology, 68(1): 18-29. DOl: 10.1016/j.jchb.2016.12.003.
Marques, R. A. B. C. 2007. Capela de Nossa Senhora da Vitória: Paleobiologia de uma série osteológica humana proveniente de Porto do Mós, Batalha. Dissertação de Mestrado em Evolução Humana, Departamento de Antropologia, Faculdade de Ciências e Tecnologia, Universidade de Coimbra.

Mizoguchi, Y. 2013. Significant among-population associations found between dental characters and environmental factors. In: Scott, G. R.; Irish, J. D. (eds.) Anthropological perspectives on dental morphology: genetics, evolution, variation. Cambridge University Press, New York: 108-125. DOI: 10.1017/CBO9780511984464.006.

Molnar, S. 1971. Human tooth wear, tooth function and cultural variability. American Journal of Physical Anthropology, 34(2): 175-190. DOI: 10.1002/ajpa.1330340204

Nichol, C. R.; Turner, C. G. II. 1986. Intra- and interobserver concordance in classifying dental morphology. American Journal of Physical Anthropology, 69(3): 299-315. DOI: 10.1002/ajpa.1330690303.

Pereira, C. M. P. 2009. Contribuição para a identificação demográfica de uma população catastrófica por parâmetros dentários População não identificada relacionada com o Terramoto de Lisboa de 1755. Tese de Doutoramento, Universidade de Lisboa.

Pinto, R. J. S. 2006. Memórias registadas: Estudo paleoantropológico de uma amostra de ossário, exumado do Hospital Geral de Santo António da cidade do Porto. Dissertação de Licenciatura em Antropologia, 
Departamento de Antropologia, Faculdade de Ciências e Tecnologia, Universidade de Coimbra.

Pinto, R. J. S. 2012. Memórias figueirenses. Estudo paleoantropologógico de um ossário exumado da Igreja Matriz de São Julião da Figueira da Foz. Dissertação de Mestrado em Evolução Humana, Departamento de Ciências da Vida, Faculdade de Ciências e Tecnologia, Universidade de Coimbra.

Pombal, C. M. P. S. 2006. Necrópole da rua dos barcos: Estudo paleoantropológico de uma amostra da população medieval da ribeira de Santarém. Dissertação de Licenciatura em Antropologia, Departamento de Antropologia, Faculdade de Ciências e Tecnologia, Universidade de Coimbra.

Rodrigues, A. C. P. 2013. A maqbara de Shantarîn. Enfermidade e saúde numa amostra esquelética de adultos. Dissertação de Mestrado em Evolução Humana, Departamento de Ciências da Vida, Faculdade de Ciências e Tecnologia, Universidade de Coimbra.

Rodrigues, Z. M. 2005. Enigmas medievais da morte em Ribeira de Santarém: Análise paleoantropológica de uma amostra de 20 esqueletos exumados da Necrópole Medieval da rua dos Barcos em Ribeira de Santarém. Dissertação de Licenciatura em Antropologia, Departamento de Antropologia, Faculdade de Ciências e Tecnologia, Universidade de Coimbra.

Scott, G. R.; Jolie, R. B. 2008. Tooth-tool use and yarn production in Norse Greenland. Alaska Journal of Anthropology 6(1/2): 253-264.
Scott, G. R.; Turner, C. G. 1997. The anthropology of modern human teeth. Dental morphology and its variation in recent human populations. Cambridge studies in Biological Anthropology. Cambridge, Cambridge University Press.

Scott, G. R.; Anta, A.; Schomberb, R.; de la Rúa, C. 2013. Basque dental morphology and the "Eurodont" dental pattern. In: Scott, G. R.; Irish, J. D. (eds.) Anthropological perspectives on dental morphology: genetics, evolution, variation. New York, Cambridge University Press: 296-318. DOI: 10.1017/CBO9780511984464.

Scott, G. R.; Maier, C.; Heim, K. 2016. Identifying and recording key morphological (nonmetric) crown and root traits. In: Irish, J. D.; Scott, G. R. (eds.) A Companion to Dental Anthropology. Chichester, Wiley-Blackwell: 247-264.

Silva, A. M. 1996. O hipogeu de Monte Canelas I (IV-III milénios AC): estudo paleobiológico da população humana exumada. Provas de Aptidão Pedagógica e Capacidade Científica, Universidade de Coimbra.

Silva, A. M. G. 2002. Antropologia funerária e paleobiologia das populações portuguesas (litorais) do Neolítico final-Calcolítico. Tese de Doutoramento em Antropologia, Universidade de Coimbra.

Silva, A. M. G. 2012. Antropologia funerária e paleobiologia das populações portuguesas (litorais) do Neolítico final-Calcolítico. Temas Universitários de Ciências Sociais e Humanas. Lisboa, Fundação Calouste Gulbenkian e Fundação para a Ciência e a Tecnologia. 
Simão, P. I. P. 2005. Regresso a Santarém medieval: Análise paleodemográfica, morfológica e paleopatológica de uma população medieval de Santarém. Dissertação de Licenciatura em Antropologia, Departa-

Skinner, M. M.; Gunz, P. 2010. The presence of accessory cusps in chimpanzee lower molars is consistent with a patterning cascade model of development. Journal of Anatomy, 217(3): 245-253. DOI: 10.1111/j.1469-7580.2010.01265.x.

Smith, B. H. 1984. Patterns of molar wear in hunter-gatherers and agriculturalists. American Journal of Physical Anthropology, 63(1): 39-56. DOI: 10.1002/ ajpa.1330630107.

Soames, J. V.; Southam, J. C. 2005. Oral Pathology. 4th edition. Oxford, Oxford University Press.

Sołtysiak, A. 2011. An R script for Smith's Mean Measure of Divergence. Bioarchaeology of the Near East, 5: 41-44.

Tereso, S. 2009. Memórias no Largo: Estudo de uma amostra osteológica humana exumada no Largo Cândido dos Reis Santarém (XVI-XVIII). Dissertação de Mestrado em Evolução Humana, Departamento de Ciências da Vida, Faculdade de Ciências e Tecnologia, Universidade de Coimbra.

Turner, C. G., Il; Nichol, C. R.; Scott, G. R. 1991. Scoring procedures for key morphological traits of the permanent dentition: The Arizona State University Dental
Anthropology System. In: Kelley, M. A.; Larsen, C. S. (eds.) Advances in Dental Anthropology. New York, Wiley-Liss: 13-31.

Tyrrell, A. 2000. Skeletal non-metric traits and the assessment of inter- and intra-population diversity: past problems and future potential. In: Cox, M.; Mays, S. (ed.). Human Osteology: in Archaeology and Forensic Science. Cambridge, Cambridge University Press: 289-306.

Vargiu, R.; Cucina, A.; Coppa, A. 2009. Italian Populations during the Copper Age: Assessment of Biological Affinities through Morphological Dental Traits. Human Biology, 81(4): 479-493. DOI: 10.3378/027.081.0406.

Wasterlain, R. S. C. N. 2006. 'Males' da Boca: estudo da patologia oral numa amostra das colecções osteológicas identificadas do Museu Antropológico da Universidade de Coimbra (finais do séc. XIX/inícios do séc. XX). Tese de Doutoramento em Antropologia, Universidade de Coimbra. Disponível em http://hdl.handle. net/10316/1580.

Willermet, C. M.; Edgar, H. J. H. 2009. Dental morphology and ancestry in Albuquerque, New Mexico Hispanics. HOMO Journal of Comparative Human Biology, 60: 207-224. 


\section{Planeta SIDA: diversidade, políticas e respostas sociais.}

Sacramento, Octávio; Ribeiro, Fernando Bessa (orgs.) 2016. Planeta SIDA: diversidade, políticas e respostas sociais. Coleção Debater o Social - 42. Vila Nova de Famalicão, Edições Húmus, Lda. ISBN: 9789897552342, 306 pp., $15.00 €$.

DOI: https://doi.org/10.14195/2182-7982_34_8

A Síndrome da Imunodeficiência Adquirida (SIDA) foi reconhecida como entidade nosológica em 1981. Desde então muito conhecimento biomédico foi produzido, tanto sobre o Vírus da Imunodeficiência Humana (VIH) como acerca dos hospedeiros. No plano das políticas para a saúde e das questões sociais, o desenvolvimento foi, igualmente massivo. No entanto, persistem disparidades colossais na representação social da doença, no acesso à terapêutica, e no estigma experienciado pelos pacientes. Disso trata o livro Planeta Sida.

Esta obra foi organizada pelo antropólogo Octávio Sacramento, docente na
Escola de Ciências Humanas e Sociais da Universidade de Trás-os-Montes e Alto Douro, e pelo sociólogo Fernando Bessa Ribeiro, atualmente no Departamento de Sociologia do Instituto de Ciências Sociais da Universidade do Minho. Estes investigadores, respetivamente, do Centro de Estudos Transdisciplinares para o Desenvolvimento (CETRAD) e do Centro Interdisciplinar de Ciências Sociais (CICS.NOVA), detêm vasta produção científica em temáticas como a prostituição transnacional, as desigualdades sociais e de género e, especificamente, sobre o VIH/SIDA.

O livro trata desta doença na atualidade, revelando os enormes avanços biomé- 
dicos e sociais mas expondo, igualmente, a persistência de medos e desconhecimentos, comuns aquando da sua descoberta. Nesse período de incertezas face ao desconhecido, o VIH foi associado aos homossexuais, aos utilizadores de drogas injetáveis e aos comportamentos ditos de risco. Outras vítimas foram pessoas com hemofilia que, durante os seus tratamentos, contraíram a infeção através de plasma contaminado, o que gerou grande mediatismo e repercussões políticas em vários países, incluindo em Portugal. No alvor da epidemia, o diagnóstico potencialmente ditava a sentença de morte.

Das memórias desse período, certamente constam as campanhas publicitárias que com alguma ousadia para a época alertavam para a prevenção da doença; a criação do projeto laço vermelho (1991) pela Visual AIDS de Nova lorque, como homenagem aos falecidos e aos que se encontravam na iminência de morrer; ou do filme Filadélfia (1993), que, ao contar com um elenco de luxo, Tom Hanks, Denzel Washington, Antonio Banderas, para dar alguns exemplos, terá ajudado a romper algumas barreiras, desmistificando conceitos acerca do VIH/SIDA.

Desses tempos longínquos, em termos do conhecimento do vírus, da passagem de doença fatal a crónica, fruto da investigação de terapêuticas mais eficazes, de luta contra o estigma, das medidas políticas e legislativas, entre tantos outros aspetos, são de algum modo ressuscita- dos neste Planeta SIDA. O livro conta com 19 autores, antropólogos e de áreas afins, que narram as suas pesquisas realizadas em diferentes contextos, alguns dos quais com situações que nos transportam para outros tempos, que deveriam ser longínquos, e que se mantêm como dura realidade nalguns países e para os portadores da doença.

Depois de uma Introdução, escrita pelos organizadores da obra, traçando o panorama mundial e descrevendo as medidas globais, nomeadamente a ambiciosa meta 90-90-90 da ONUSIDA para 2020 (ou seja, que $90 \%$ das pessoas infetadas estejam diagnosticadas, que, dessas, 90\% se encontrem em tratamento e que 90\% das pessoas em tratamento estejam com a infeção controlada), surgem 12 capítulos com foco regional.

Da Austrália, o texto de Paul Sendziuk descreve o percurso do país desde as campanhas pioneiras de considerável risco e ousadia, sobre o uso de preservativo, destinadas aos homossexuais, bem como a forte mobilização de grupos e associações. Os seis estados e dois territórios australianos não reagiram da mesma forma, nem em simultâneo, em termos preventivos, informativos e legislativos, com consequências distintas. Os resultados obtidos são analisados em comparação com as ações realizadas pelos Estados Unidos da América.

$\mathrm{Na}$ China, o controlo e a restrição de movimento dos seropositivos, o não 
reconhecimento da doença pelas autoridades até 2002, e a situação atual do acompanhamento dos doentes pelas ONG internacionais e pelas GONGO, governamentais, são relatados por Tiantian Zheng, investigadora de temáticas relacionadas com a prostituição.

O texto do antropólogo Carlos GuiIherme Valle, que tem pesquisado o impacto da epidemia da SIDA, descreve a caminhada e militância no Brasil com a participação de figuras públicas do mundo da música e da política.

Sobre Portugal, os organizadores do livro em coautoria com Marta Maia, investigadora com vasto trabalho sobre comportamentos sexuais, traçam a evolução do perfil dos doentes e da legislação, listam as iniciativas da sociedade civil a operar no território nacional bem como a fraca mobilização.

O texto de Aderemi Ajala e Prisca Adejumo, ambos com estudos publicados sobre os Yoruba da Nigéria, trata da representação do VIH/SIDA à luz da responsabilidade coletiva e entendida como consequência da perda dos valores pela sociedade.

Sophie Hohmann e Saodat Olimova, com extenso trabalho na área dos estudos migratórios, narram as dificuldades e a desinformação dos emigrantes Tajiques na Federação Russa, facultando um enquadramento acerca da doença nesse país em que a situação epidemiológica é, estranhamente, recente.
As experiências e as representações do $\mathrm{VIH}$, do consumo de drogas e da prostituição pelos trabalhadores agrícolas do interior profundo do Sul dos Estados Unidos da América são apresentados por Keith Bletzer, investigador que se tem dedicado a estas temáticas e à sua divulgação.

Da Tunísia, ou genericamente sobre África, Sofiane Bouhdiba relata as dificuldades de rastreio e do acompanhamento terapêutico dos portadores refugiados e o facto de muitos países impedirem a entrada, 59 à escala global, ou não concederem asilo político a seropositivos.

Em Marrocos, constatam-se as diferenças entre a legislação punitiva, designadamente para mulheres com crianças fora do casamento, e a compreensão dos profissionais de saúde e intervenientes associativos sobre adultos e crianças portadores de $\mathrm{VIH}$.

A pesquisa etnográfica realizada na Índia revela a forte discriminação e as perceções erróneas que atingem as muIheres vítimas da doença. De igual modo se apreende o quotidiano das mulheres seropositivas do Camboja e os recursos à contraceção e à prática do aborto, realizadas na (quase) total ausência da biomedicina.

Dos Países e Territórios das llhas do Pacífico, com especial ênfase em Palau e Fiji, é dada a conhecer a dura realidade das e dos trabalhadores do sexo que vivem sob forte pressão policial e inexistência de acesso a cuidados de saúde. 
Realizado este périplo demonstrativo da cobertura global da obra, expressa no título, um aspeto que sobressai é a dissonância nas abordagens seguidas nos diversos capítulos. Dito de outro modo, o subtítulo diversidade, políticas e respostas sociais não aparenta ter sido o mote da obra, com cada investigador a explicitar no seu contexto de análise estes conteúdos, mas, sim, o aglutinador da multiplicidade de pesquisas expostas.

O livro com grande trabalho de tradução para português pelos organizadores, já que foram traduzidos 10 dos 13 capítulos, tem uma escrita acessível, com várias notas dos tradutores que tornam a leitura adequada a públicos diversos, constituindo, assim, uma referência sobre a temática para o universo de leitores lusófonos, abarcando públicos diversos tais como:

- investigadores e docentes das Ciências Sociais/Humanas e das Ciências da Saúde, ONG e demais organizações envolvidas na prevenção, tratamento e investigação do VIH/SIDA;

- decisores políticos, pois não basta conhecer a biologia do vírus, a química dos fármacos e a economia dos custos. Sem se entender as pessoas e as suas idiossincrasias, esta enfermidade não é, nem será, verdadeiramente combatida;

- estudantes que queiram iniciar trabalho etnográfico nesta área (ou mesmo noutras doenças).

A edição é cuidada, com boas dimensões de mancha de texto e de fontes, e resistente ao manuseamento.
Esta obra mostra o caminho percorrido e as vitórias obtidas globalmente, mas também as disparidades atuais e as situações dramáticas em que vivem e morrem muitas pessoas. Na imensidão social e cultural que caracteriza a humanidade, constitui uma janela aberta, nem sempre para uma paisagem luminosa, do que é o Planeta SIDA.

\section{Ana Luísa Santos}

Centro de Investigação em Antropologia e Saúde Departamento de Ciências da Vida Universidade de Coimbra, Coimbra, Portugal alsantos@antrop.uc.pt 